\title{
Aqueous carbon black dispersions stabilized by sodium lignosulfonates
}

\author{
Sreedhar Subramanian ${ }^{1,2}$ (1) $\cdot$ Gisle Øye ${ }^{1}$ \\ Received: 27 July 2020 / Revised: 14 April 2021 / Accepted: 18 April 2021 / Published online: 6 May 2021 \\ (C) The Author(s) 2021
}

\begin{abstract}
Six different sodium lignosulfonates with varying degrees of sulfonation (0.14-1.29 sulfonate groups per phenylpropane unit) and molecular weights $\left(M_{w}=6000-330,000 \mathrm{~g} / \mathrm{mol}\right)$ were evaluated for their ability to disperse carbon black in aqueous media. Rheological and particle size measurements of carbon black dispersions indicated that lignosulfonates with low degree of sulfonation function as good carbon black dispersants. The dispersion efficiency did not correspond directly to the amount of lignosulfonate adsorbed on the surface of carbon black. The lignosulfonates have an ability to enhance the colloidal stability by electrostatic repulsion, and the likely mechanism of stabilization is a combination of electrostatic repulsion and steric hindrance.
\end{abstract}

Keywords Carbon black $\cdot$ Rheology $\cdot$ Lignosulfonate $\cdot$ Degree of Sulfonation

\section{Introduction}

Carbon black refers to the commercial form of solid carbon produced by thermal decomposition or thermal combustion of hydrocarbons. About $90 \%$ of the carbon black produced worldwide is used in rubber industry, while the remaining $10 \%$ is utilized in non-rubber industries including printing inks, plastics, and coatings [1]. Carbon blacks are characterized by their particle size, structure, and surface chemistry, and these three properties determine the dispersibility of carbon black. The primary particle size of carbon black is typically around $10 \mathrm{~nm}$, but they tend to aggregate via covalent bonding, followed by formation of larger agglomerates (microns size) due to Van der Waals forces. In order to make it easier to handle, carbon black is typically sold in the form of pellets [2].

An aqueous dispersion of carbon black is generally a requirement to prepare printing ink and latex masterbatches [3,

Sreedhar Subramanian

sreedhar.subramanian@borregaard.com

1 Ugelstad Laboratory, Department of Chemical Engineering, Norwegian University of Science and Technology (NTNU), Sem Sælandsvei 4, N-7491 Trondheim, Norway

2 Present address: Borregaard ASA, Hjalmar Wessels vei 6, 1701 Sarpsborg, Norway
4]. However, carbon blacks are inherently hydrophobic due to their high elemental carbon content, typically greater than $95 \%$, and have a low wettability, thereby making it difficult to disperse them in aqueous medium [5]. Carbon blacks do consist of oxygen containing groups like carbonyl, carboxyl, pyrone, phenol, quinone, lactone, and ether groups bound to their surface. Dispersions with low carbon black loadings can be achieved by mixing carbon black particles in water under high shear conditions $[6,7]$, but preparation of dispersions with high carbon black loading ( $\geq 20 \mathrm{wt} \%$ ) requires the use of a dispersant to prevent excessive viscosity build-up [4]. Several dispersants have been used for dispersing carbon black including cationic surfactants [8-10], anionic surfactants [4, 9-12], and non-ionic surfactants [9, 13-15].

Cationic surfactants like cetyltrimethylammonium bromide (CTAB) and cetyltrimethylammonium chloride (CTAC) have been found to efficiently disperse carbon black particles $[5,8]$. The colloidal stability of the carbon black particles in presence of CTAB has been attributed to the monolayer adsorption of $\mathrm{CTAB}$, which provides stability against aggregation through a combination of electrostatic repulsion and steric hindrance [8]. In the case of non-ionic surfactants belonging to nonylphenol ethoxylates (NPE) class, the hydrophobic nonylphenol groups adsorb strongly on the surface of carbon black, while the steric stabilization is provided by hydrophilic ethylene oxide (EO) groups. Gupta and Bhagwat [9] observed an increase in carbon black colloidal stability with an increase in number of EO groups in the NPE surfactant. However, a similar study by Sis 
and Birinci [13] indicated that the NPE with 10 moles of EO per surfactant molecule showed the best performance. This was attributed to the superior wetting ability of NPE molecule with intermediate number of EO groups grafted. In another study with nonylphenol propylene oxide-ethylene oxide (NP PO-EO) surfactants where the EO content was varied, it was observed that carbon black dispersions stabilized with high molecular weight surfactant resulted in dispersions with higher viscosity than those stabilized with low molecular weight surfactant [14]. Among the anionic surfactants, sodium dodecylbenzene sulfonate (SDBS) has been found to be more effective in dispersing carbon black than sodium dodecyl sulfate (SDS) due to better wetting nature of SDBS [5]. The other commonly used anionic surfactants for dispersing carbon black are sulfonic acid derivatives $[4,15]$.

The present work investigates the ability of sulfonic acid derivates, especially sodium lignosulfonate to stabilize carbon black dispersions. Lignosulfonates are produced by sulfite pulping process of wood, and they have a broad molecular weight distribution $\left(M_{w}=5000-60,000 \mathrm{~g} / \mathrm{mol}\right)$ and varying degree of sulfonation (0.4-0.7 sulfonate group per phenylpropane unit) [16]. The typical structure of lignosulfonate obtained by sulfite pulping is given in Fig. 1. The presence of sulfonate group increases the water solubility of lignosulfonate since the sulfonate group can act as both hydrogen bond donor and acceptor. The sulfonyl, carboxylate, and phenolic hydroxyl groups impart hydrophilic character, while the hydrocarbon backbone imparts hydrophobic character to the lignosulfonate. The sulfonyl groups mainly cover the surface of lignosulfonate, while carboxylate and phenolic hydroxyl groups are suggested to be located in the hydrophobic core of the lignosulfonate [17]. The presence of charged functional groups helps lignosulfonates to impart electrostatic stabilization. The structure of lignosulfonate has been a point of controversy. Goring initially suggested a spherical microgel model describing lignosulfonates to be consisting of randomly coiled crosslinked polyaromatic chains with sulfonate groups at the surface [18] and later proposed a disc-like microgel model based on observation of lignosulfonates adsorbed on carbon film using transmission electron microscopy (TEM) [19], while Myrvold [20] described lignosulfonate as a randomly branched polyelectrolyte based on scaling analysis of intrinsic viscosity variation with molecular weight. Recent studies using small angle X-ray scattering (SAXS) and light scattering experiments indicate that lignosulfonates exist as oblate spheroid with an axial ratio of 3.5 [21, 22].

Lignosulfonates have found wide use as both flocculant and dispersant due to its good water solubility [23]. Qin and coworkers found that sodium lignosulfonates (Na-LS) have a greater ability to disperse coal particles than calcium lignosulfonates (Ca-LS) since the presence of divalent calcium counterion led to a destruction of electrical double layer [24]. Zhou and coworkers fractionated a Na-LS and found that fraction with intermediate molecular weight had the best ability to disperse coal water slurry [25]. Li and coworkers used a 1:1 ratio of carbon black to Na-LS, and the Na-LS was found to

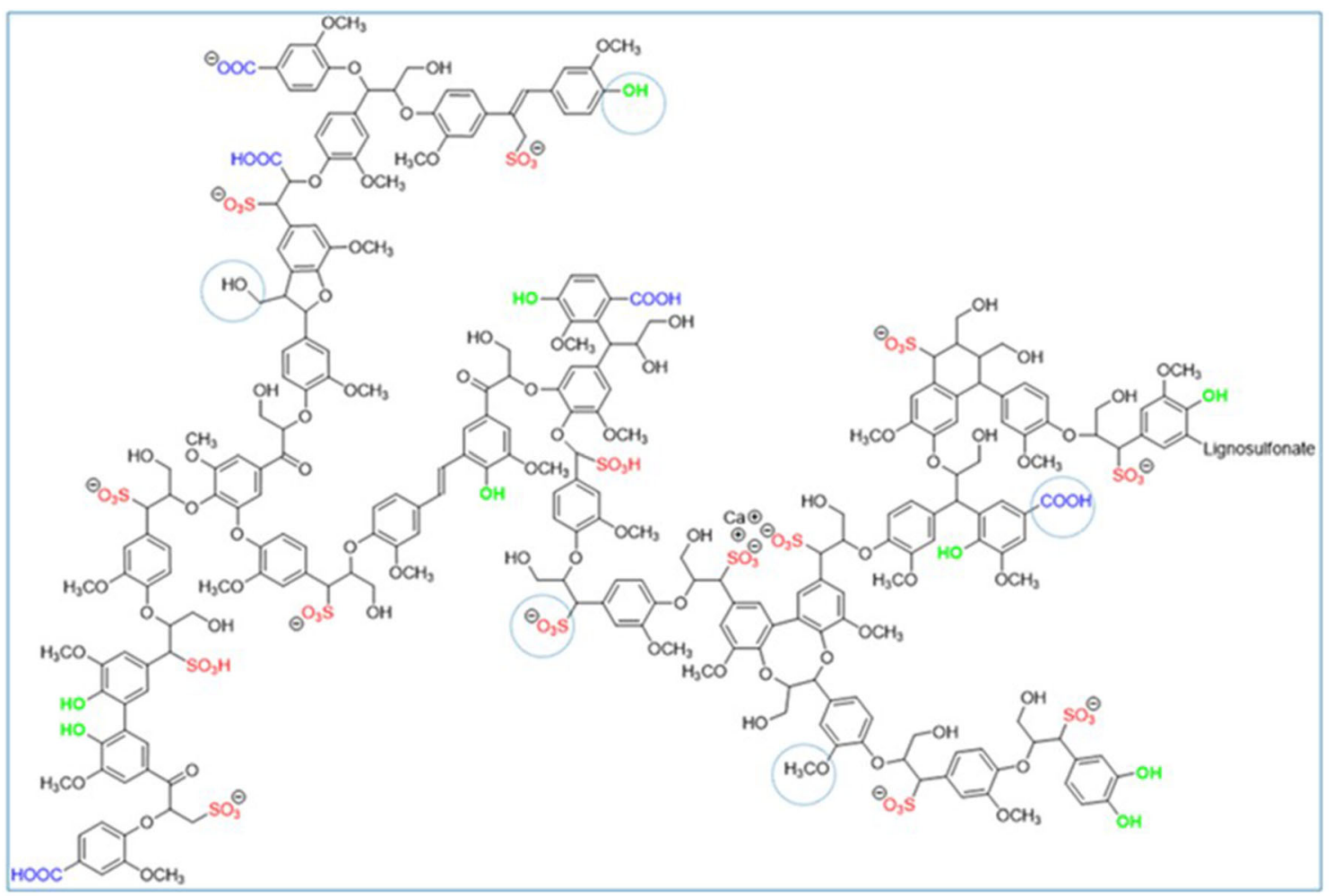

Fig. 1 Lignosulfonate structure (Courtesy Borregaard) 
encapsulate the carbon surface via $\pi-\pi^{*}$ interaction [26]. Dispersions of carbon black using lignosulfonate with good stability have also been reported [12].

The aim of present study is to identify the properties of lignosulfonates which contribute to their ability to disperse carbon black. Six different sodium lignosulfonates are used in this study, and the contribution of different functional groups, molecular weight, and hydrophobicity in influencing the lignosulfonate's dispersion ability is investigated. The criteria to evaluate lignosulfonate performance was based on combination of dispersant's ability to minimize aggregation/ agglomeration of carbon black particles over time and its ability to reduce the viscosity of the carbon black dispersion. We hope that the findings in the study will help industry in modifying/tailoring lignosulfonate to enhance their carbon black dispersing ability.

\section{Materials and method}

\section{Materials}

\section{Carbon black}

A low structure specialty grade carbon black "Black Pearls 430" supplied by Cabot Corporation was used in this study. A low structure carbon black typically contains a smaller number of primary particles $(<20)$ per aggregate [27]. The specifications of carbon black provided by Cabot are given in Table 1 [28].

\section{Lignosulfonate}

Six softwood lignosulfonate samples (identified by DP numbers) provided by Borregaard $\mathrm{A} / \mathrm{S}$ were used in this study. The characterization of the lignosulfonates is given in Table 2 and was determined by the methods described by Myrvold [29]. The samples contained $<0.5 \mathrm{wt} \%$ reducing sugars. The lignosulfonates were used as received without any further purification or fractionation.

Table 1 Typical values of Cabot Black Pearl 430

\begin{tabular}{ll}
\hline Property & Typical values \\
\hline Iodine adsorption number $(\mathrm{mg} / \mathrm{g})$ & 82 \\
Oil absorption number $(\mathrm{ml} / 100 \mathrm{~g})$ & 72 \\
Tint $(\%)$ & 102 \\
Density at $23{ }^{\circ} \mathrm{C}\left(\mathrm{kg} / \mathrm{m}^{3}\right)$ & 375 \\
\hline
\end{tabular}

\section{Other materials}

The other materials used in the study were sodium hydroxide (AnalaR NORMAPUR, VWR), sodium chloride (EMSURE ACS, Merck), hydrochloric acid (37\%, AnalaR NORMAPUR, VWR), and deionized water.

\section{Methods}

\section{Determination of BET specific surface area of carbon black by $\mathrm{N}_{2}$-adsorption}

The specific surface area of carbon black was determined using Tristar 3000 Gas adsorption analyzer (Micrometrics Inc.). Approximately $100 \mathrm{mg}$ of carbon black was degassed under vacuum at room temperature for $1 \mathrm{~h}$ and at $300^{\circ} \mathrm{C}$ up to $0.07 \mathrm{mbar}$ for $12 \mathrm{~h}$. The adsorption and desorption isotherms were measured at relative pressures in the range $0.01-1$. The specific surface area was then calculated based on the Brunauer-Emmet-Teller (BET) method in the relative pressure range $0.01-0.30$ [30].

\section{Particle size measurements}

The particle size distribution of dilute carbon black solution was determined using Mastersizer 3000 (Malvern Instruments) fitted with the Hydro EV cell and a $1000 \mathrm{ml}$ beaker. A $5 \mathrm{wt} \%$ carbon black dispersion in $5 \mathrm{mM} \mathrm{NaCl}$ was initially prepared via sonication for $10 \mathrm{~min}$, followed by shearing using ultra-turaxx (IKA T25 digital with S $25 \mathrm{~N}-10 \mathrm{G}$ dispersing tool) at 20,000 rpm for $10 \mathrm{~min}$. Two to three drops of the carbon black dispersion were added to the Mastersizer beaker which contained $800 \mathrm{~g}$ of $5 \mathrm{mM} \mathrm{NaCl}$. The dilute dispersion was sonicated for $5 \mathrm{~min}$, and the particle size was measured for $60 \mathrm{~min}$ after end of sonication. A constant stirring speed of $2500 \mathrm{rpm}$ was maintained throughout the experiment. For particle size measurement with lignosulfonate, a stock solution of $2 \mathrm{wt} \%$ lignosulfonate in $5 \mathrm{mM} \mathrm{NaCl}$ was initially prepared. The desired amount of $2 \mathrm{wt} \%$ lignosulfonate solution was added to the carbon black particles before subjecting it to $10 \mathrm{~min}$ sonication and shearing using ultraturaxx (20,000 rpm, $10 \mathrm{~min})$. The rest of the procedure was the same as described for measurements with carbon black.

\section{Adsorption isotherm}

Initially, a solution of $1000 \mathrm{ppm}$ (by weight) of lignosulfonate was prepared by dissolving $30 \mathrm{mg}$ of lignosulfonate in deionized water. Several solutions of lignosulfonate in concentration range $25-150 \mathrm{ppm}$ were then prepared by dilution using deionized water. The UV-vis spectra of the solutions were then measured in the spectral range $200-800 \mathrm{~nm}$. The absorbance at characteristic maximum at $280 \mathrm{~nm}$ (which 
Table 2 Characterization of lignosulfonate samples

\begin{tabular}{lllllll}
\hline Sample & DP-3383 & DP-3384 & DP-3385 & DP-3537 & DP-3635 & DP-3760 \\
\hline DM (wt\%) & 95.5 & 94.8 & 95.6 & 93.8 & 94.4 & 94.6 \\
$M_{w}(\mathrm{~g} / \mathrm{mol})$ & 77,000 & 43,000 & 22,000 & 6000 & 330,000 & 87,000 \\
$M_{n}(\mathrm{~g} / \mathrm{mol})$ & 3200 & 2700 & 2700 & 1800 & 4000 & 2800 \\
$M_{w} / M_{n}(-)$ & 24 & 16 & 8 & 3 & 83 & 31 \\
Org.S (wt\%) & 5.4 & 5.7 & 9.4 & 2.1 & 4.8 & 5.2 \\
COOH (wt\%) & 8.6 & 10.0 & 8.3 & 14.9 & 10.7 & 10.2 \\
Ph.OH (wt\%) & 2.0 & 1.6 & 1.3 & 1.9 & 1.5 & 1.7 \\
Methoxyl (wt\%) & 10.8 & 8.8 & 7.3 & 15.4 & 4.4 & 7.6 \\
\hline
\end{tabular}

Note that functional groups are given as \% of dry matter (DM). Org.S refers to organic sulfur and $\mathrm{Ph} . \mathrm{OH}$ to phenolic hydroxyl group corresponds to the $\pi-\pi^{*}$ electron transition of the C9 guaiacyl unit) was used for calibration curve [31].

The adsorption isotherm of lignosulfonate was determined using $1 \mathrm{wt} \%$ carbon black in $0.05 \mathrm{M} \mathrm{NaCl}$ solution. The concentration of lignosulfonate in carbon black dispersion was varied between 0.01 and $0.3 \mathrm{wt} \%$ (or $0.1-3 \mathrm{~g} / \mathrm{l}$ ). The lignosulfonates were allowed to adsorb on carbon black for $24 \mathrm{~h}$ by placing them on a benchtop shaker at $250 \mathrm{rpm}$. The dispersion was then centrifuged at 14,500 rpm (RCF: $14,000 \times$ g) and filtered through $0.2 \mu \mathrm{m}$ PTFE filter, and the filtered solution was diluted with deionized water (typically up to below $80 \mathrm{ppm}$ lignosulfonate concentration in order to be within the Beer-Lambert absorbance range) before measuring the UV-vis absorbance.

\section{Rheology measurements}

The rheology measurements were performed using Anton Paar Physica MCR 102 rheometer fitted with concentric cylinder (CC) geometry.

Rheology of concentrated carbon black dispersions Initially, $4 \mathrm{wt} \%$ lignosulfonate solutions were prepared in $0.1 \mathrm{~N} \mathrm{NaCl}$. Required amounts of carbon black, lignosulfonate solution, and $0.1 \mathrm{~N} \mathrm{NaCl}$ were added together to obtain a dispersion containing $20 \mathrm{wt} \%$ carbon black $+3 \mathrm{wt} \%$ lignosulfonate. The dispersion was then sonicated for $10 \mathrm{~min}$ followed by shearing using ultra turaxx (20,000 rpm, $10 \mathrm{~min})$. The $\mathrm{pH}$ of dispersion was adjusted to $\mathrm{pH} 10$ using $50 \% \mathrm{NaOH}$ solution. The dispersion was left overnight on a bench-top shaker at $250 \mathrm{rpm}$. Before the rheology measurement, the sample was sonicated for $10 \mathrm{~min}$ and shaken manually.

The following protocol was used for rheology measurement: sample was pre-sheared at $1000 \mathrm{~s}^{-1}$ for $2 \mathrm{~min}$, followed by a waiting time of $2 \mathrm{~min}$. The viscosity measurement was then performed in the range $10^{-3}$ to $10^{3} \mathrm{~s}^{-1}$ over $10 \mathrm{~min}$. A 2 min waiting time was given, followed by measurement of storage and loss modulus under constant imposed strain at
$1 \mathrm{~Hz}$ for $60 \mathrm{~min}$. The rheological measurements were performed at $25^{\circ} \mathrm{C}$.

Flow curve of concentrated lignosulfonate solution Lignosulfonate solutions of $35 \mathrm{wt} \%$ in deionized water were prepared and sonicated for $30 \mathrm{~min}$, followed by placing on a benchtop shaker at $300 \mathrm{rpm}$ overnight at room temperature. The $\mathrm{pH}$ of the solutions were then adjusted to $\mathrm{pH} 10$ using $50 \% \mathrm{NaOH}$ solution. The lignosulfonate solutions were then placed on a benchtop shaker for $1 \mathrm{~h}$, followed by sonication for $10 \mathrm{~min}$ before measurement of flow curve. The following protocol was used for rheology measurement: sample was presheared at $1000 \mathrm{~s}^{-1}$ for $2 \mathrm{~min}$ in rheometer, followed by a waiting time of $2 \mathrm{~min}$. The viscosity measurement was then performed in the range $10^{-1}$ to $10^{3} \mathrm{~s}^{-1}$ over $6 \mathrm{~min}$ at $25^{\circ} \mathrm{C}$.

\section{Zeta potential determination}

The zeta potential measurements were carried out in Zetasizer Nano ZS (Malvern Instruments) using the universal dip cell kit. A $5 \mathrm{wt} \%$ carbon black dispersion was initially prepared in $10 \mathrm{mM} \mathrm{NaCl}$ by sonication (10 min) and shearing using ultraturaxx (20,000 rpm, $10 \mathrm{~min})$. The dispersion was left to stand overnight at room temperature. The dispersion was then diluted to $200 \mathrm{ppm}$ by addition of $10 \mathrm{mM} \mathrm{NaCl}$. Solutions of $2 \mathrm{ppm}$ carbon black in $10 \mathrm{mM} \mathrm{NaCl}$ were then prepared by further dilution, followed by $\mathrm{pH}$ adjustment ( $\mathrm{pH} 3-10)$ using $\mathrm{HCl}$ and $\mathrm{NaOH}$ solutions. Zeta potential measurements of supernatant solution were performed on the same day (ca. $3 \mathrm{~h}$ after sample preparation). The supernatant was sonicated for $5 \mathrm{~min}$ before measurement. All measurements were carried out at $25^{\circ} \mathrm{C}$, and the samples were equilibrated for $2 \mathrm{~min}$ in zetasizer before starting the zeta potential measurements. Typically, 5-7 measurements were performed for each sample with $20 \mathrm{~s}$ waiting time between each measurement. The instrument measures the electrophoretic mobility, which is then converted to zeta potential using Henry's equation and Smoluchowski approximation [32]. In addition, particle size 
measurement was also performed for carbon black sample at $\mathrm{pH} 10$.

For zeta potential measurement of carbon black with lignosulfonate, a stock solution of $2 \mathrm{wt} \%$ lignosulfonate in $10 \mathrm{mM}$ $\mathrm{NaCl}$ was prepared. The desired amount of $2 \mathrm{wt} \%$ lignosulfonate solution was then added to carbon black particles and then diluted with $10 \mathrm{mM} \mathrm{NaCl}$. The rest of the procedure was the same as described for only carbon black measurements.

\section{Results}

BET measurements indicated that the carbon black particles had a specific surface area $=76.4 \pm 0.7 \mathrm{~m}^{2} / \mathrm{g}$. Similarly, the carbon black particles were found to exist in the size range of 40-700 nm as shown in Fig. 2, with the intensity weighted mean size (z-average) of ca. $200 \mathrm{~nm}$.

\section{Effect of lignosulfonate on carbon black particle size}

Figure 3 shows the variation in particle size distribution of carbon black in a $5 \mathrm{mM} \mathrm{NaCl}$ solution with time. The measurement immediately at the end of sonication (i.e., at $t=0$ min) indicates the presence of ca. 5 vol\% particles below 1 $\mu \mathrm{m}$. A shift in particle size distribution towards higher particle sizes is observed with time ( $t=30$ and $60 \mathrm{~min}$ ) in addition to presence of particles of bigger size (ca. $100 \mu \mathrm{m})$, thereby indicating the agglomeration of the carbon black particles with time.

The effect of adding DP-3537 on the carbon black particle size distribution is shown in Fig. 4, measured 1 min after the end of sonication. As the concentration of DP-3537 was increased from 0.05 to $0.20 \mathrm{wt} \%$, the particle size distribution shifts towards the lower size range. When the dispersant concentration is 0.15 or $0.20 \mathrm{wt} \%$, we can observe a significantly higher volume of particles in sub-micron range, thereby indicating a better dispersion of carbon black particles on higher dosage of dispersant. Figure 5 shows the evolution of median diameter (d50) of carbon black particles with time after the end of sonication. In the case of carbon black particles (with no lignosulfonate added), we can observe an increase in median diameter in the first 10 min (after the sonication has been switched off) due to carbon black particle aggregation. The median diameter of particles stabilizes at around $6 \mu \mathrm{m}$ after 15-20 min. The high agitator speed of $2500 \mathrm{pm}$ during measurement ensured that the particles remain suspended in the solution and not sediment. As the concentration of DP3537 was increased, the median diameter decreased from ca. $5.8 \mu \mathrm{m}$ (at $t=60 \mathrm{~min}$ ) with no lignosulfonate (LS) added to ca. $1.8 \mu \mathrm{m}$ (at $t=60 \mathrm{~min}$ ) in presence of $0.10 \mathrm{wt} \% \mathrm{DP}-3537$. The median diameter decreased further to $1 \mu \mathrm{m}$ in presence of $0.15 \mathrm{wt} \%$ DP-3537, while it reduced even further to $0.2 \mu \mathrm{m}$ when 0.20 wt\% DP-3537 was used. However, only the data obtained for the first $30 \mathrm{~min}$ met the curve fitting quality criteria (residual $<2 \%$ ) for experiment with 0.15 wt $\%$ DP3537, while only the data for the first 10 min met the curve fitting quality criteria for measurements performed with $0.2 \%$ DP-3537. This can mainly be attributed to the optical parameter artefact (artefact caused by difference in input values of refraction index and absorption of particles compared to their actual values). Thus, it was decided to use $0.10 \mathrm{wt} \%$ lignosulfonate loading as the basis for comparing the performance of the different lignosulfonates.

The effect of different lignosulfonates on the carbon black median diameter is shown in Fig. 6. At $t=0 \mathrm{~min}$, we observe a significant reduction in the median diameter of carbon black particles in presence of lignosulfonate. However, even in presence of lignosulfonate, a gradual increase in the median diameter of carbon black particles with time was observed with
Fig. 2 Particle size distribution of carbon black in $10 \mathrm{mM} \mathrm{NaCl}$

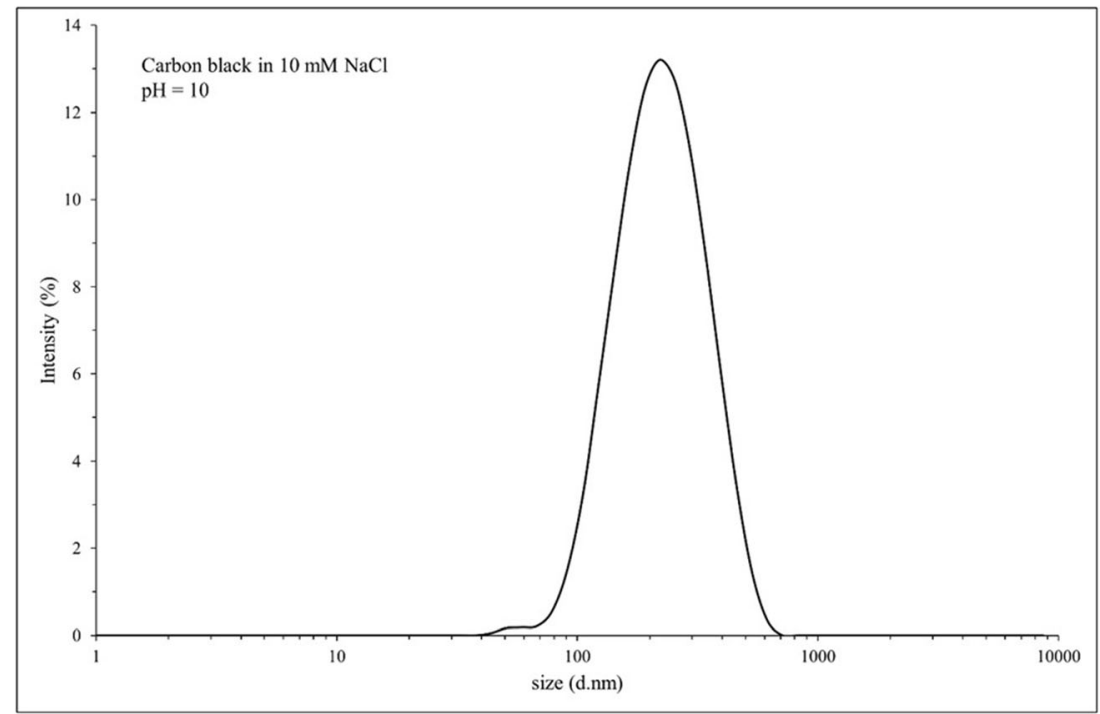


Fig. 3 Particle size distribution of $5 \%$ carbon black dispersion in $5 \mathrm{mM} \mathrm{NaCl}$ solution at $\mathrm{pH} \sim 6$ in absence of lignosulfonate

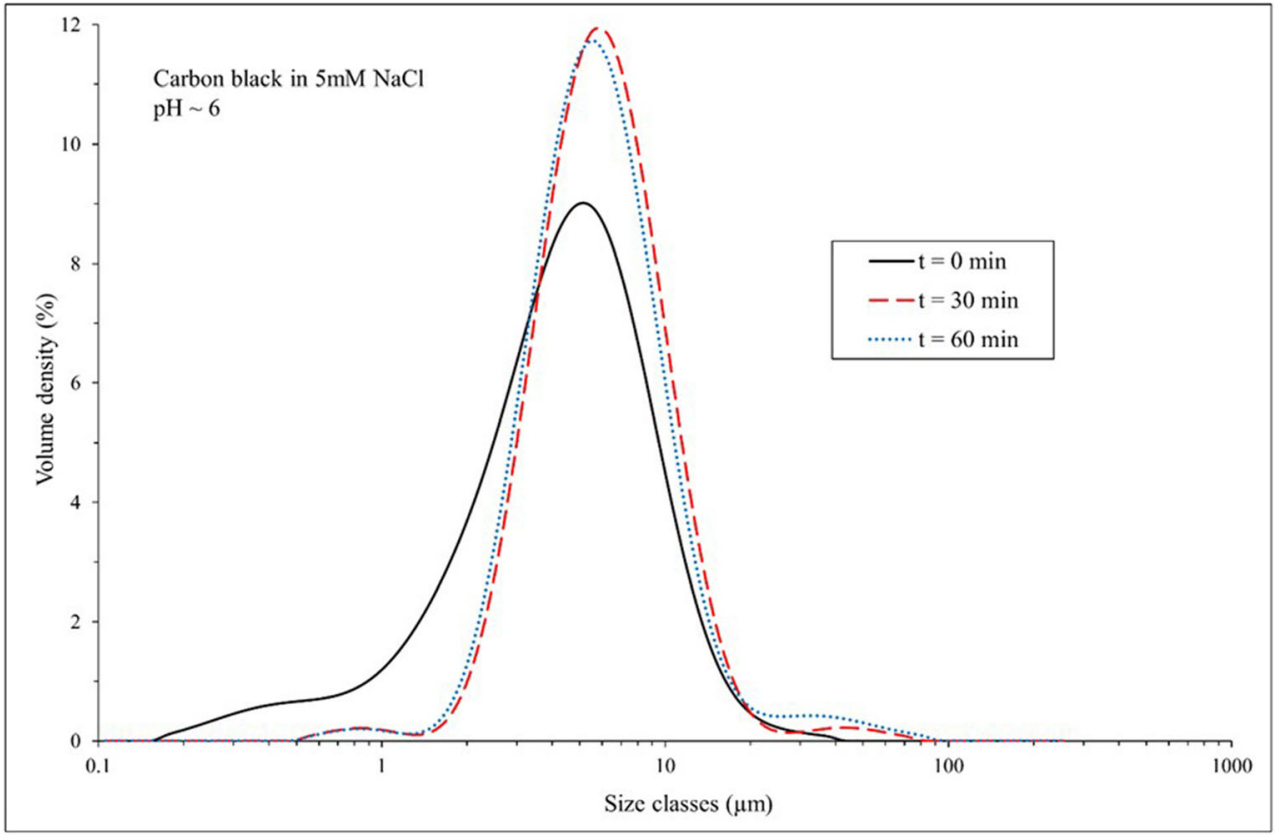

$0.10 \mathrm{wt} \%$ lignosulfonate loading, thereby indicating the aggregation of carbon black particles. DP-3537 exhibited the best dispersing performance as indicated by the lowest median diameter values, followed by DP-3383. The lignosulfonates DP-3635 and DP-3760 were however found to be less effective in stabilizing carbon black dispersion. It should be noted that there was no $\mathrm{pH}$ adjustment done for these experiments. The $\mathrm{pH}$ was measured at the end of each experiment and found to be $6.0 \pm 0.1$.

Figure 7 shows the picture of dilute carbon black dispersions (20 ppm) with different lignosulfonates at varying times.
Significant sedimentation can be observed in dispersion without lignosulfonate when left standing for a day. A similar observation is also obtained with dispersion containing DP3635 and DP-3760. The remaining 4 dispersions are more stable, with the dispersion containing DP-3537 showing the least sedimentation after 9 days, followed by DP-3383.

The effect of $\mathrm{pH}$ on the performance of DP-3537 was investigated at pH 6 and 10, respectively. As seen in Fig. 8, pH had only a minor effect on the median diameter of carbon black particles when $0.10 \mathrm{wt} \%$ DP-3537 was added. The most probable reason for this observation is that the zeta potential of
Fig. 4 Particle size distribution of 5 wt\% carbon black dispersion with different concentration of DP-3537 in $5 \mathrm{mM} \mathrm{NaCl}$ measured $1 \mathrm{~min}$ after end of sonication

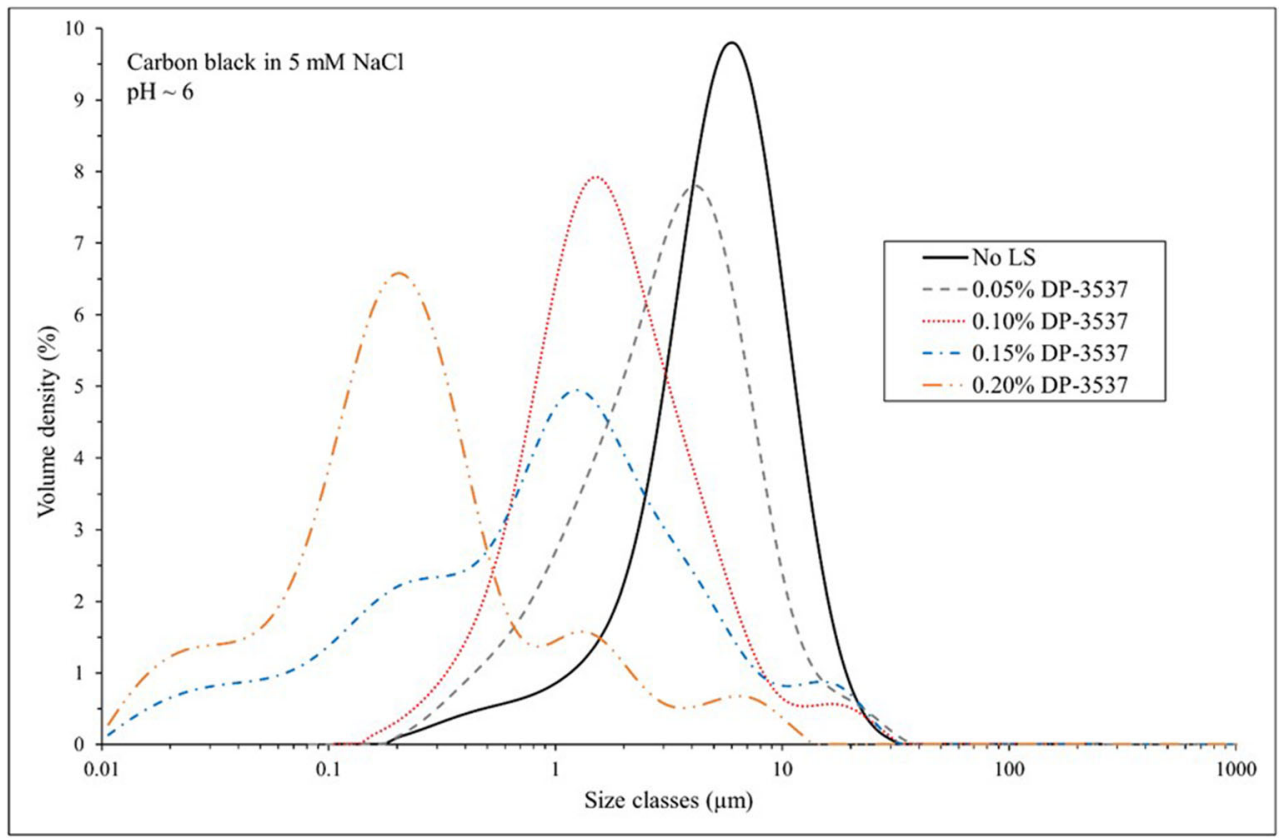


Fig. 5 Effect of varying concentration of DP-3537 on the carbon black median diameter at $\mathrm{pH} \sim 6$ in presence of $5 \mathrm{mM} \mathrm{NaCl}$. LS refers to lignosulfonate

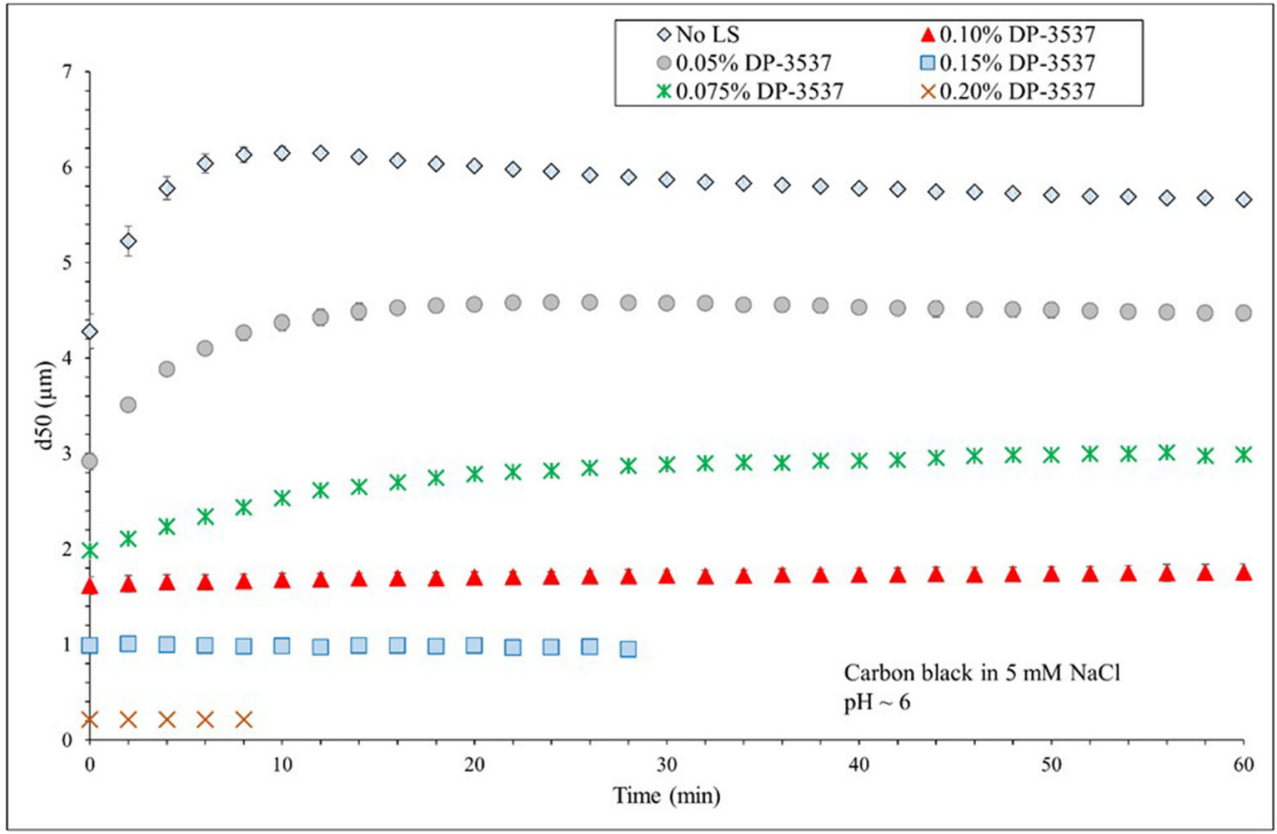

carbon black particles with adsorbed DP-3537 remains almost constant above $\mathrm{pH}$ 6. We can however observe a slightly greater tendency for carbon black particles to aggregate with time at $\mathrm{pH} 10$, as indicated by a gradual increase in the particle size with time during the experiment.

\section{Adsorption isotherms}

Initially, the UV-vis absorption of different lignosulfonate samples in deionized water was determined, and the calibration curve was obtained based on the absorption at $280 \mathrm{~nm}$.
The calibration curve values for different lignosulfonates obtained by line fitting are given in Table 3 .

The amount of lignosulfonate adsorbed on carbon black was calculated based on the equation:

$$
\Gamma=\frac{\left(c_{i}-c\right) \cdot v}{m_{\text {carbon black }} \cdot\left(A_{s p}\right)_{\text {carbon black }}}
$$

where $\Gamma$ is the amount of lignosulfonate adsorbed $\left(\mathrm{mg} / \mathrm{m}^{2}\right), c_{i}$ the initial lignosulfonate concentration $(\mathrm{g} / \mathrm{l}), c$ the supernatant lignosulfonate concentration $(\mathrm{g} / \mathrm{l}), v$ the total volume $(\mathrm{ml}), m$ carbon black the mass of carbon black added $(\mathrm{g})$ and $\left(A_{s p}\right)_{\text {carbon }}$
Fig. 6 Effect of different lignosulfonates on the median diameter of $5 \mathrm{wt} \%$ carbon black dispersion at $\mathrm{pH} \sim 6$ in presence of $5 \mathrm{mM} \mathrm{NaCl}$

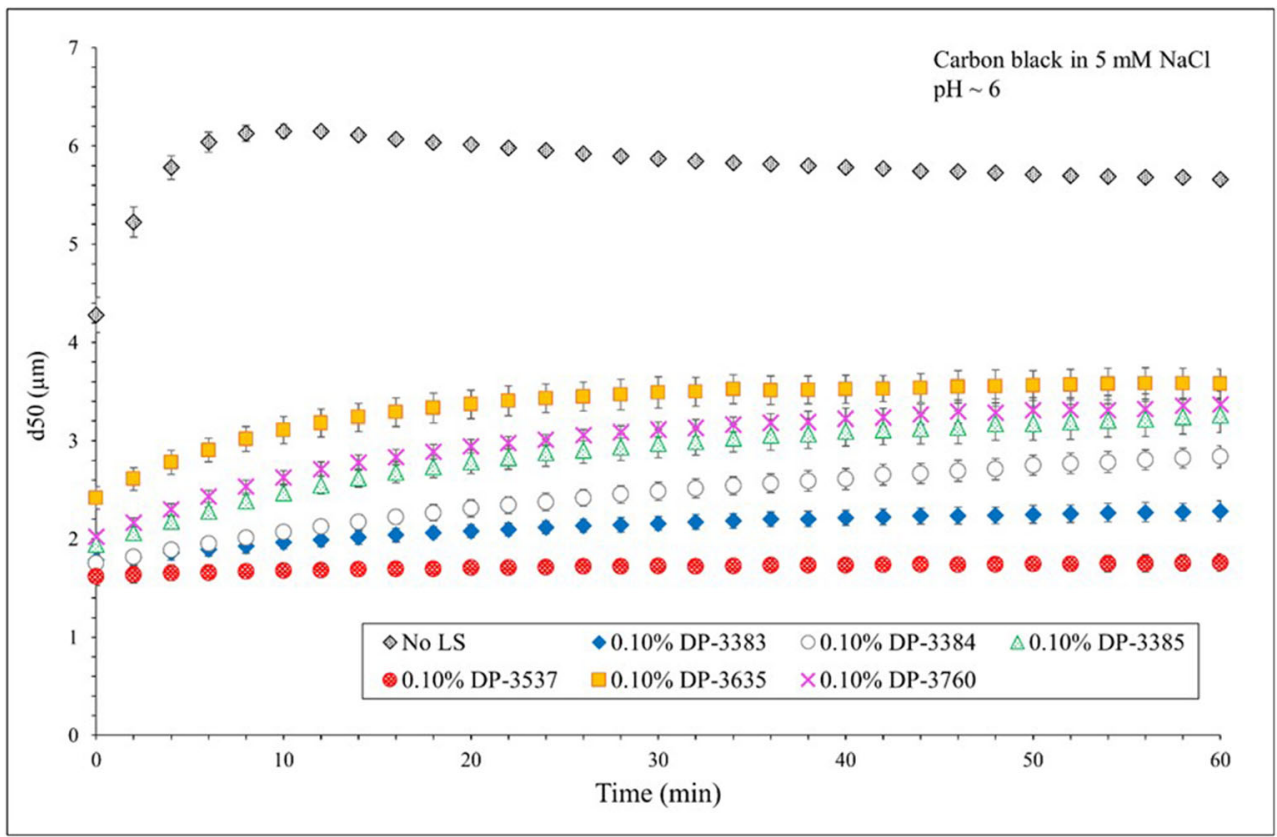



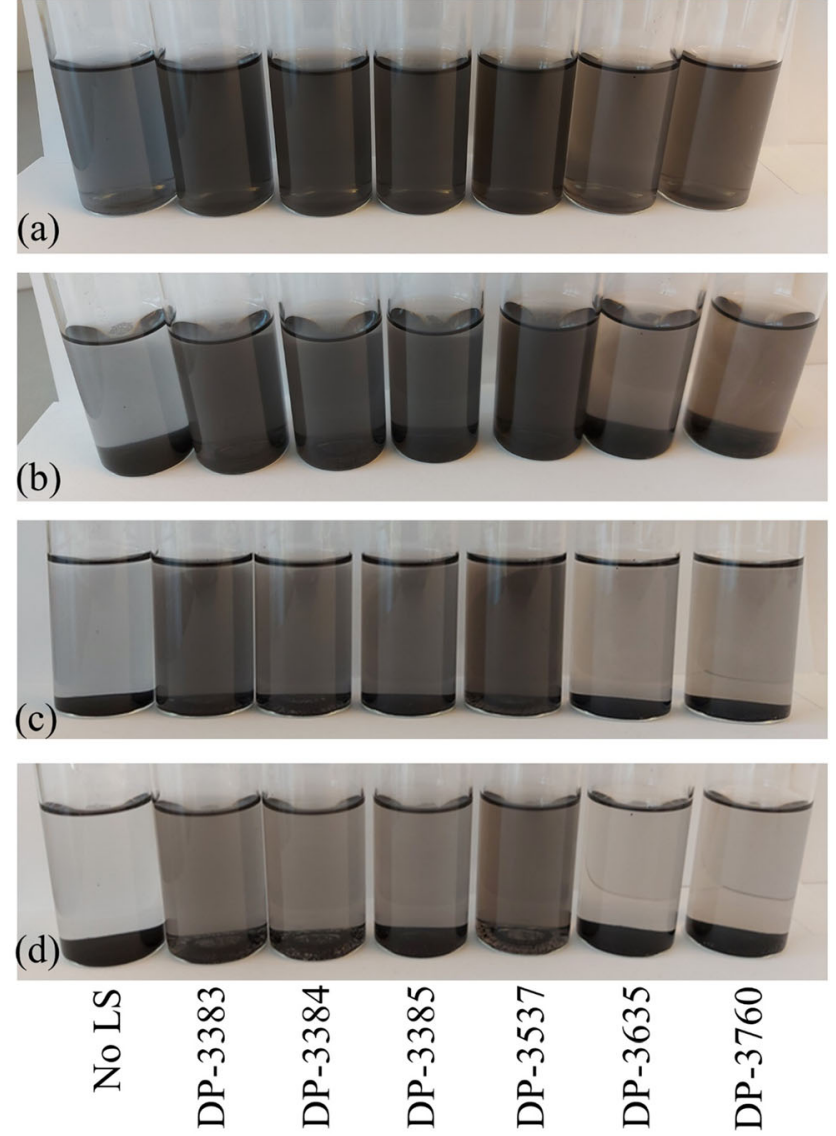

Fig. 7 Image of carbon black dispersions (20 ppm) with different lignosulfonates taken $\mathbf{a}$ immediately after preparation, $\mathbf{b}$ after 1 day, $\mathbf{c}$ after 3 days, $\mathbf{d}$ after 9 days
Table 3 UV-vis calibration factor for different lignosulfonate at $280 \mathrm{~nm}$

Lignosulfonate

UV-vis calibration factor (slope)

\begin{tabular}{ll}
\hline DP-3383 & 0.0146 \\
DP-3384 & 0.0100 \\
DP-3385 & 0.0088 \\
DP-3537 & 0.0307 \\
DP-3635 & 0.0122 \\
DP-3760 & 0.0117 \\
\hline
\end{tabular}

black the BET surface area of carbon black $\left(\mathrm{m}^{2} / \mathrm{g}\right)$.

Figure 9 shows the adsorption isotherm of the different lignosulfonates on carbon black with $0.05 \mathrm{M} \mathrm{NaCl}$ background electrolyte. The adsorption experiments were performed at the natural $\mathrm{pH}$ of the lignosulfonate samples, and it varied between $\mathrm{pH} 8$ and 10. A higher concentration of $\mathrm{NaCl}$ was used than that in particle size measurements in order to ensure that the ionic strength of the solution shows only a minor change $(<2 \mathrm{mM})$ even on addition of $0.3 \mathrm{wt} \%$ lignosulfonate (the highest concentration used in the adsorption experiments). The concentration of $\mathrm{NaCl}$ is however not high enough to completely eliminate the role of electrostatic interaction. In addition, since carbon black is a negatively charged substrate, Van der Waals forces or hydrophobic interactions also act as a driving for adsorption of the anionic lignosulfonate on its surface. The highest adsorption capability was exhibited by DP-3635, and this could be due to its high
Fig. 8 Effect of $\mathrm{pH}$ on the median diameter of $5 \mathrm{wt} \%$ carbon black dispersion with 0.075 and 0.10 wt $\%$ DP-3537

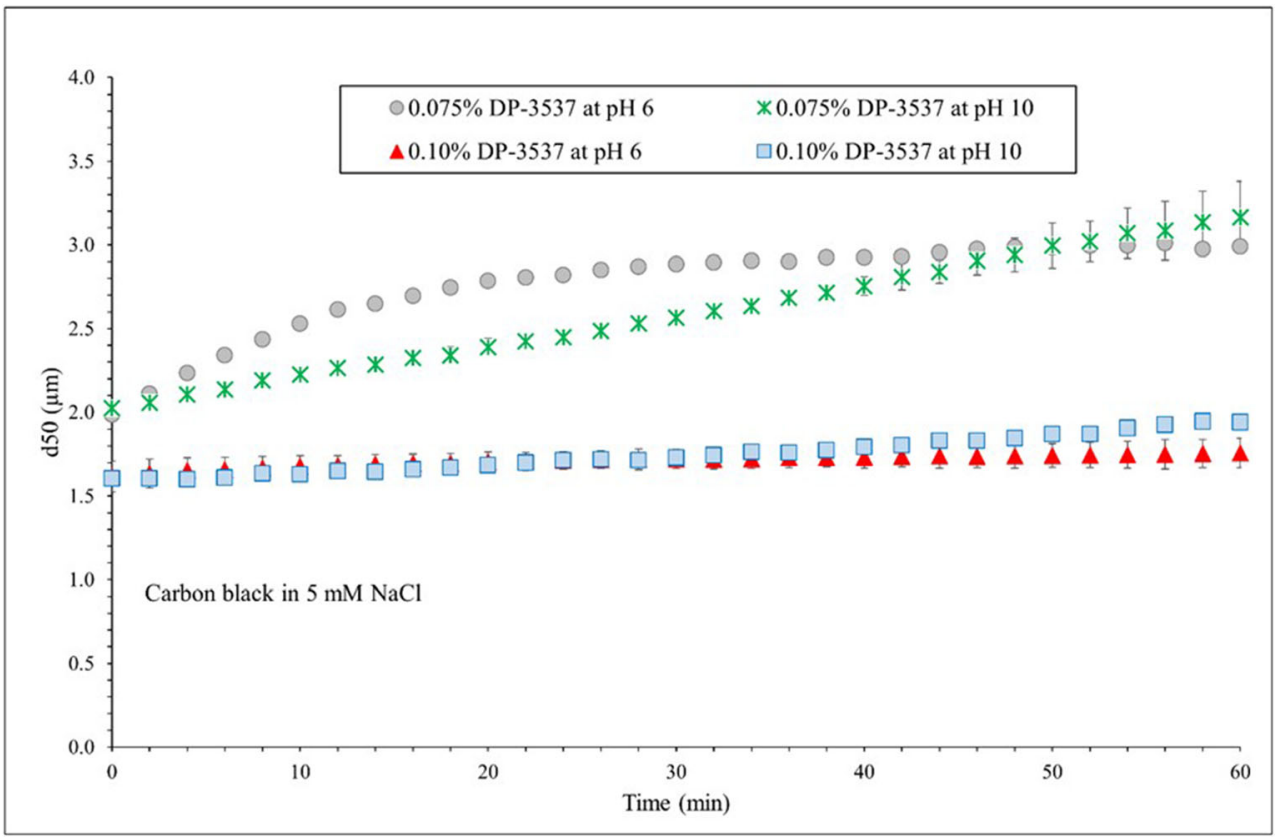


Fig. 9 Adsorption isotherm of lignosulfonate on $1 \mathrm{wt} \%$ carbon black along with Langmuir isotherm fitting

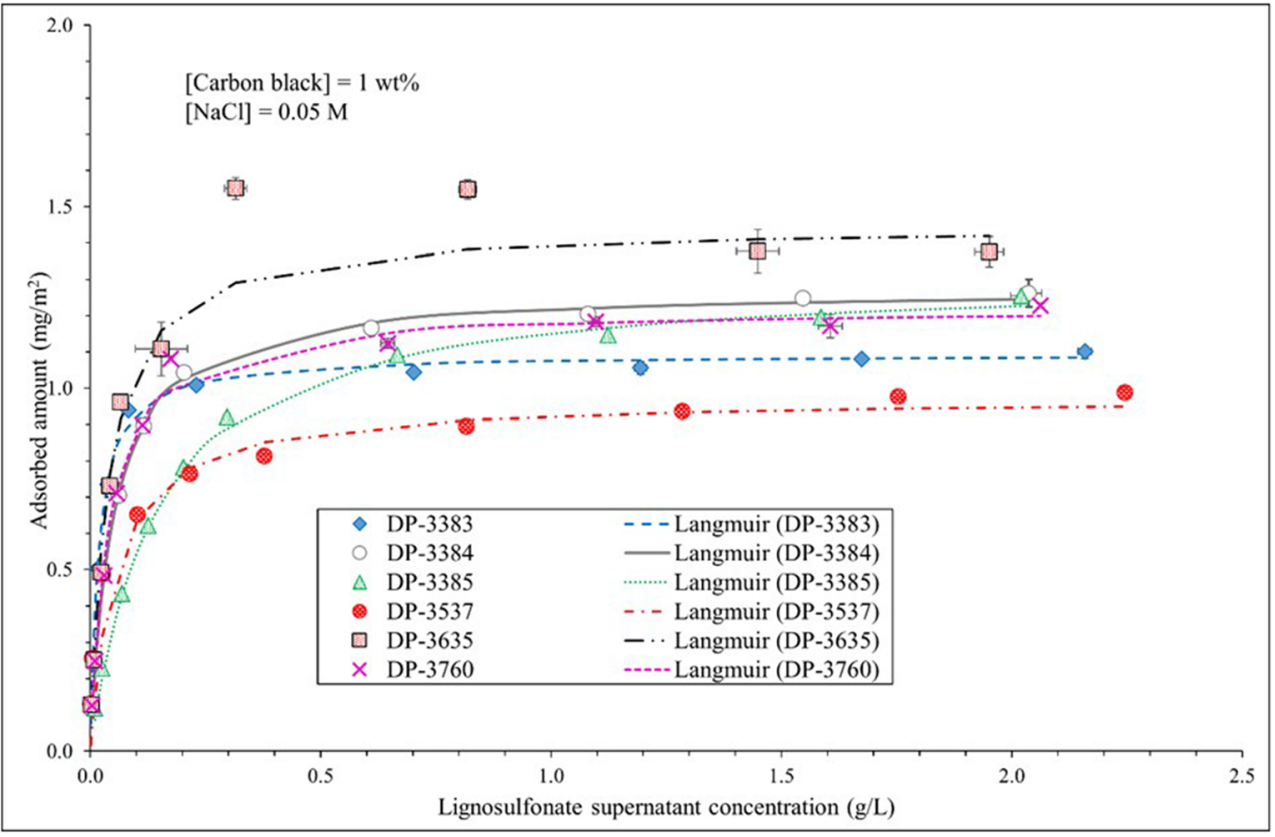

molecular weight. Similarly, DP-3537 (lignosulfonate with low molecular weight) showed the least adsorption capability on carbon black.

Figure 9 also shows the Langmuir fit for the adsorption isotherm based on the equation:

$\Gamma=\frac{\Gamma_{\max } \cdot k \cdot c}{1+k \cdot c}$

where $\Gamma$ refers to adsorbed lignosulfonate amount $\left(\mathrm{mg} / \mathrm{m}^{2}\right)$, $\Gamma_{\max }$ the maximum lignosulfonate adsorption $\left(\mathrm{mg} / \mathrm{m}^{2}\right), c$ the supernatant lignosulfonate concentration $(\mathrm{g} / \mathrm{l})$, and $k$ is a constant. The values of $\Gamma_{\max }$ and $k$ obtained for different lignosulfonate samples are given in Table 4. It should however be noted that the Langmuir fitting for DP-3635 is poor at intermediate concentrations, since a significantly higher adsorption was observed experimentally. We do not have an explanation for this reproducible observation.

Table 4 Langmuir isotherm fitting parameters $\left(\Gamma_{\max }\right.$ and $k$ ) for different lignosulfonates on carbon black along with the $\mathrm{pH}$ during the adsorption experiments

\begin{tabular}{llll}
\hline Lignosulfonate & $\mathrm{pH}$ & $\Gamma_{\max }\left(\mathrm{mg} / \mathrm{m}^{2}\right)$ & $k$ \\
\hline DP-3383 & $8.3 \pm 0.4$ & $1.10 \pm 0.00$ & $54.14 \pm 3.93$ \\
DP-3384 & $8.0 \pm 0.2$ & $1.28 \pm 0.01$ & $20.06 \pm 0.05$ \\
DP-3385 & $8.9 \pm 0.2$ & $1.32 \pm 0.00$ & $7.30 \pm 0.22$ \\
DP-3537 & $8.1 \pm 0.3$ & $0.96 \pm 0.01$ & $18.78 \pm 1.06$ \\
DP-3635 & $9.5 \pm 0.4$ & $1.45 \pm 0.01$ & $26.06 \pm 1.19$ \\
DP-3760 & $9.5 \pm 0.4$ & $1.21 \pm 0.01$ & $24.80 \pm 0.22$ \\
\hline
\end{tabular}

\section{Rheology}

A higher $\mathrm{NaCl}$ concentration $(0.1 \mathrm{~N})$ was used for rheology experiments to minimize the effect of lignosulfonate addition in measurements. The ionic strength varies between 0.107 and $0.117 \mathrm{~N}$ in the carbon black dispersion prepared with lignosulfonates depending on the molecular weight of the lignosulfonate used. The lignosulfonate loading for $20 \mathrm{wt} \%$ carbon dispersion was optimized using DP-3384 and DP3383. Dispersion prepared with $<2$ wt $\%$ DP-3383 and DP3384 respectively became very viscous during shearing with ultra-turrax and did not flow even on vigorous shaking manually. The carbon black dispersion with $3 \mathrm{wt} \%$ DP-3384 did not exhibit excessive viscosity build-up. Hence, 3 wt $\%$ lignosulfonate loading was selected for comparing the lignosulfonate performance. It should be noted that it was possible to prepare free-flowing carbon black dispersions with DP-3537 at low loading ( $1 \mathrm{wt} \%$ ), while it was not possible to prepare the same with other dispersants at $1 \mathrm{wt} \%$ loading. This indicates that DP-3537 has a much better performance at lower dosage compared to the other lignosulfonates tested in this study.

The flow curve of the concentrated carbon black dispersion with $3 \mathrm{wt} \%$ lignosulfonate loading is shown in Fig. 10. A flowable dispersion with DP-3635 could not be prepared due to very high viscosity build-up during shearing with ultra-turrax, and hence, the flow curve was not measured. The remaining dispersions are predominantly shear thinning, with DP-3383 exhibiting superior performance (almost Newtonian behavior), followed by DP-3537, DP-3384, DP-3385, and 
Fig. 10 Flow curve of 20 wt $\%$ carbon black dispersion with $3 \mathrm{wt} \%$ lignosulfonate in $0.1 \mathrm{M}$ $\mathrm{NaCl}$ at $\mathrm{pH} 10$

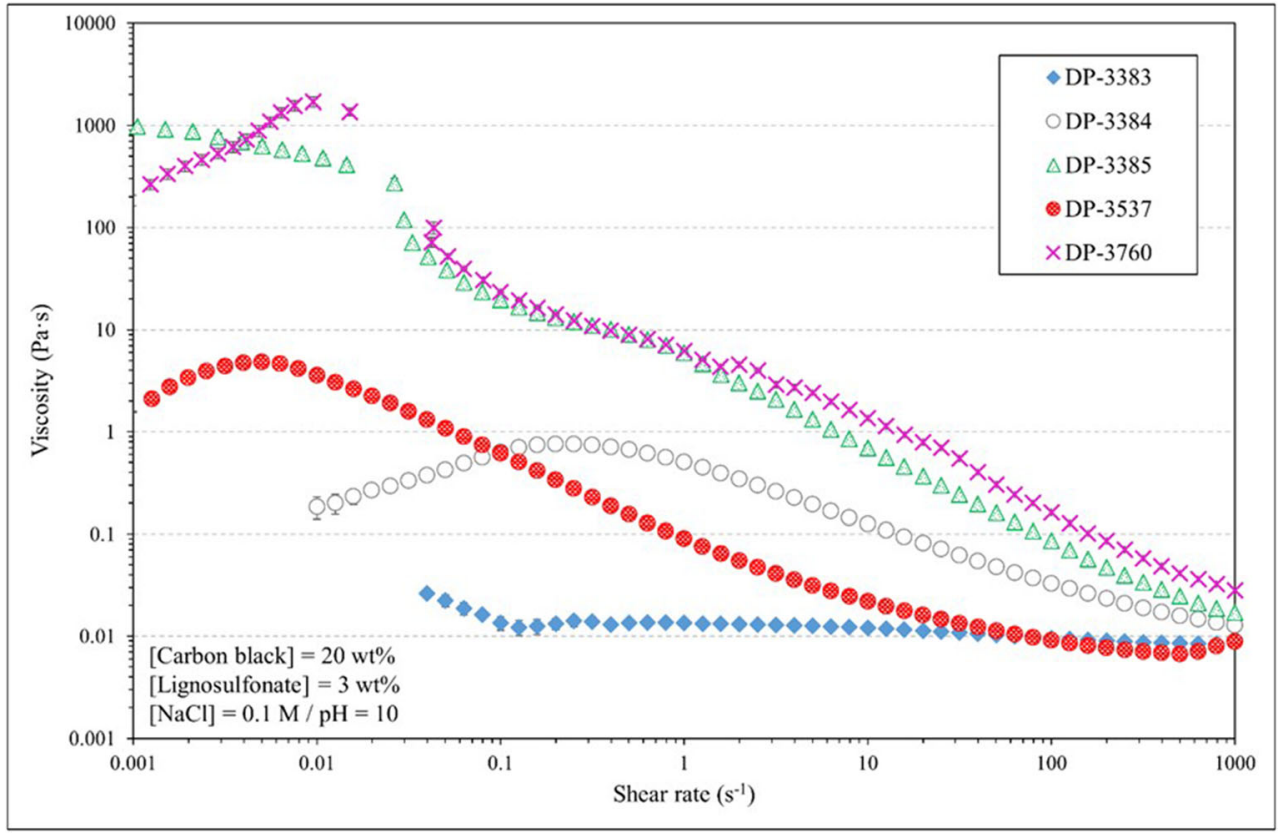

DP-3760. Figure 11 shows the evolution of storage modulus with time for the dispersion prepared with different lignosulfonates. In the case of the dispersions with DP-3537 and DP3383 , an internal structure with a low storage modulus $\left(\mathrm{G}^{\prime}\right)$ is formed immediately after breakage, and the modulus remains almost constant during the measurement time of $60 \mathrm{~min}$. The other dispersions show an increase in modulus with time, thereby indicating the potential for these systems to build up internal network with very large storage modulus on longer storage.
The flow curve of concentrated lignosulfonate solutions is given in Fig. 12. The concentrated 35 wt\% DP-3384, DP3385, DP-3537, and DP-3760 solutions show a Newtonian behavior, while $35 \mathrm{wt} \%$ DP-3383 and $25 \mathrm{wt} \%$ DP-3635 show shear thinning behavior. The shear thinning behavior indicates that the closely packed lignosulfonates can interact with each other, thereby forming a network.
Fig. 11 Evolution of storage $\left(\mathrm{G}^{\prime}\right)$ and loss $\left(\mathrm{G}^{\prime \prime}\right)$ moduli with time of $20 \mathrm{wt} \%$ carbon black dispersion with $3 \mathrm{wt} \%$ lignosulfonate in $0.1 \mathrm{M} \mathrm{NaCl}$ at $\mathrm{pH} 10$

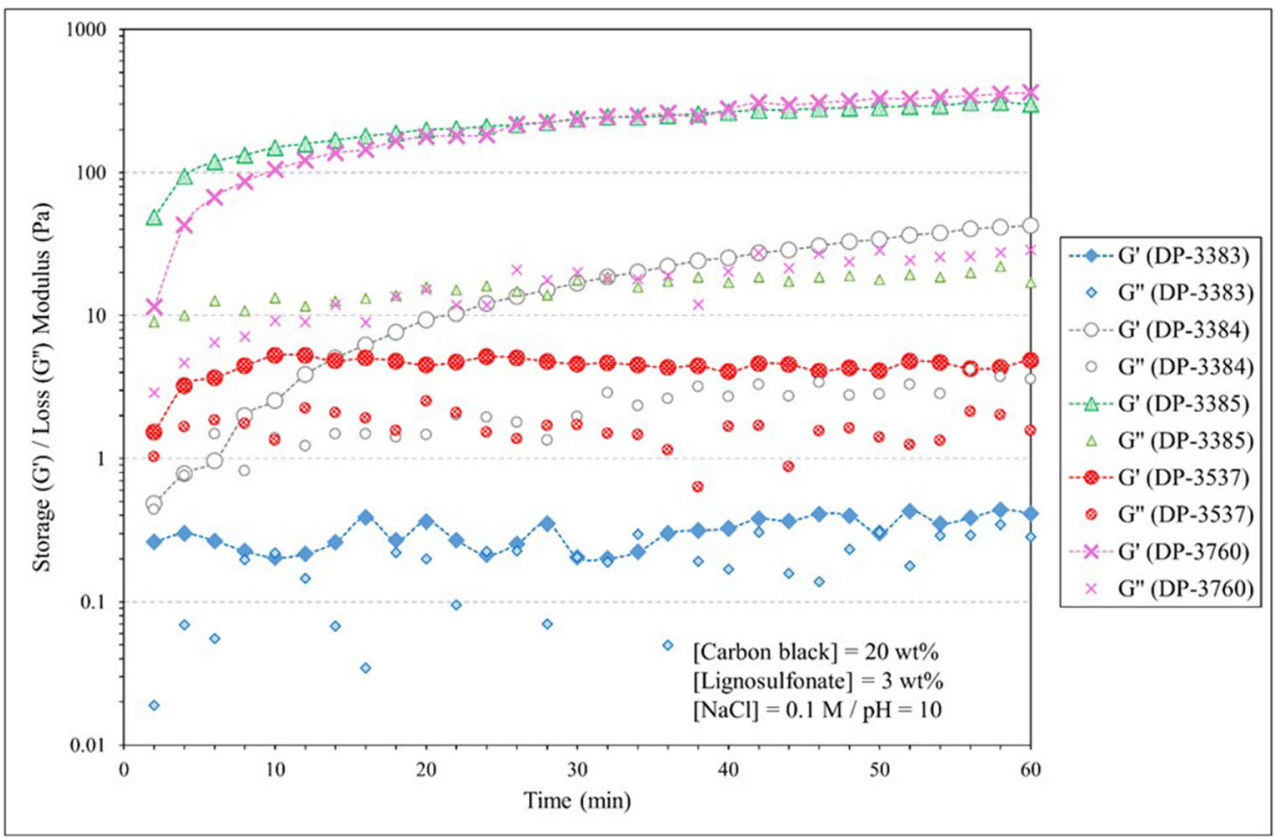


Fig. 12 Flow curve of 35 wt $\%$ lignosulfonate solutions in $0.1 \mathrm{~N}$ $\mathrm{NaCl}$ solution at $\mathrm{pH} 10$. Note that $25 \mathrm{wt} \%$ solution was used for DP3635

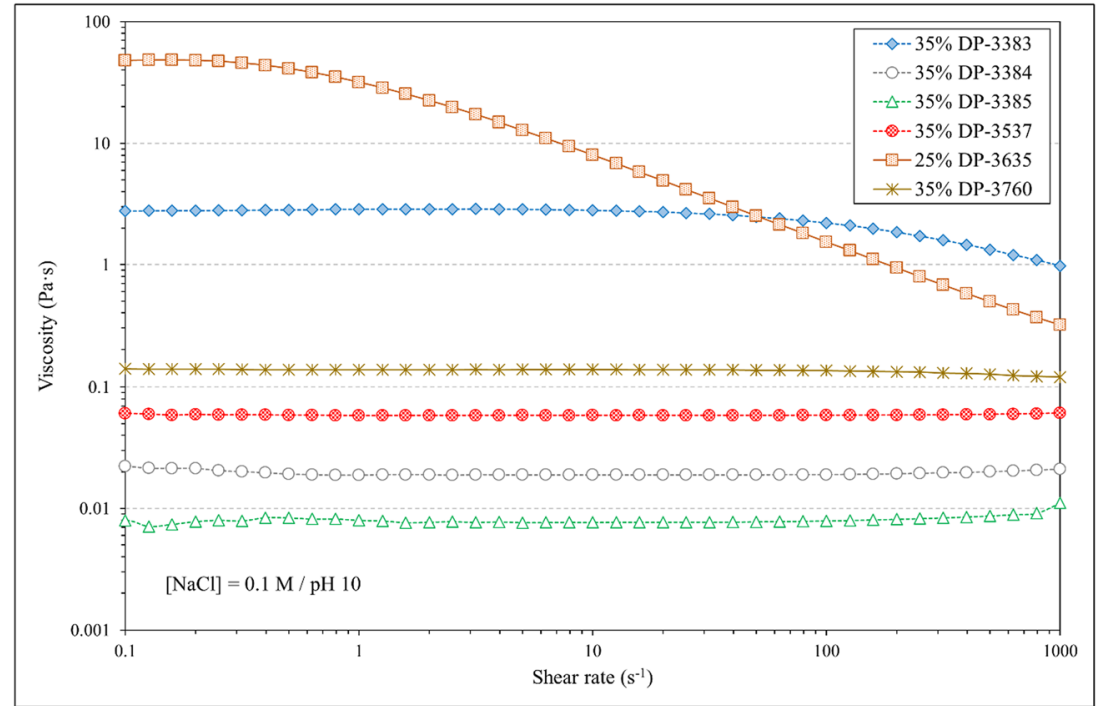

\section{Zeta potential}

The zeta potential of carbon black particles with and without lignosulfonate over the $\mathrm{pH}$ range $3-10$ is shown in Fig. 13. The experiments were performed with $10 \mathrm{mM} \mathrm{NaCl}$ as background electrolyte in order to have the Henry function $=1.5$ (Smoluchowski approximation). The isoelectric point (or point of zero charge) of carbon black particles is below $\mathrm{pH}$ 3. The zeta potential of carbon black is $-8 \mathrm{mV}$ at $\mathrm{pH} 3$ and then continues to decrease further as the $\mathrm{pH}$ is increased up to $\mathrm{pH} 10$, reaching a value of $-40 \mathrm{mV}$. This indicates that the carbon black particles used in this study inherently have a better stability at $\mathrm{pH}>6$. The zeta potential of carbon black particles was initially tested at two different loadings of DP3537 ( 0.20 and $0.75 \mathrm{wt} \%)$ to determine the lignosulfonate loading needed for further testing. In presence of $0.20 \mathrm{wt} \%$ DP-3537, the zeta potential of the carbon black particles decreased by a further $10 \mathrm{mV}$ over the entire $\mathrm{pH}$ range, thereby showing the ability of DP-3537 to enhance stability against agglomeration by electrostatic stabilization. The zeta potential of carbon black particles with $0.20 \mathrm{wt} \%$ DP-3537 indicated slightly better electrostatic stability than with $0.75 \mathrm{wt} \%$ DP3537. Generally, a monolayer adsorption of dispersant is sufficient to provide electrostatic stabilization, and the presence of excess dispersant can lead to destabilization. Hence, the evaluation of remaining lignosulfonate samples was done at
Fig. 13 Zeta potential of carbon black $(\mathrm{CB})$ particles with adsorbed lignosulfonate in $10 \mathrm{mM} \mathrm{NaCl}$ solution at $25^{\circ} \mathrm{C}$

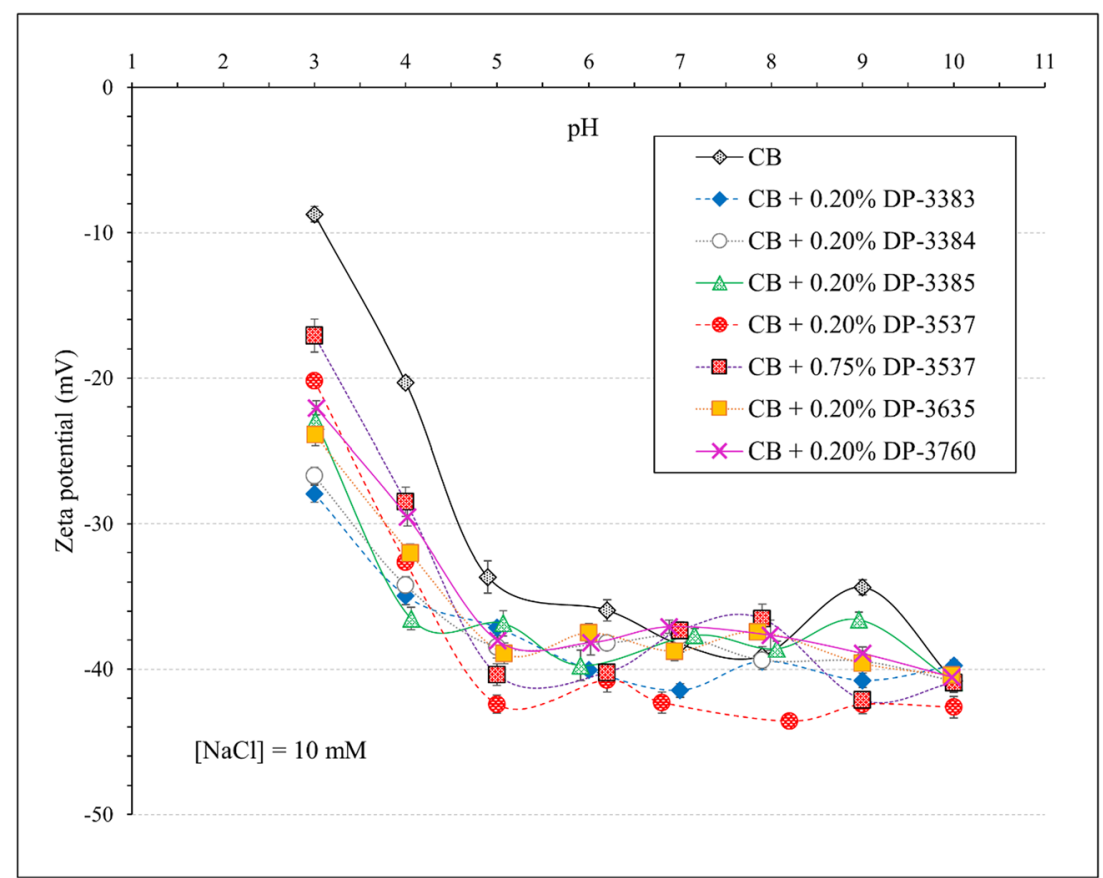


$0.20 \mathrm{wt} \%$ loading. The effect of different lignosulfonates on the zeta potential of carbon black particles is more pronounced at $\mathrm{pH}<5$. The sulfonic group being a base of a strong acid is expected to be completely deprotonated under experimental conditions. The pKa of carboxylate and phenolic hydroxyl groups are 4-5 and 11.5-11.7, respectively [33, 34]. Hence, in the $\mathrm{pH} 3-5$ range, the changes in the zeta potential are mainly due to the deprotonation of carboxylate groups. A reduction in the zeta potential of carbon black particles with adsorbed lignosulfonates by ca. $10 \mathrm{mV}$ indicates an enhanced stability imparted by the adsorbed lignosulfonate. However, none of the lignosulfonate samples could decrease the zeta potential of particles below $-45 \mathrm{mV}$.

\section{Discussion}

Different concentrations of $\mathrm{NaCl}$ were used as background electrolyte for particle size measurement, adsorption experiments, rheology, and zeta potential measurements, primarily to ensure less variation in ionic strength on addition of lignosulfonate. Higher salt content can lead to a decrease in the electrostatic repulsion due to shielding of functional groups in lignosulfonate and make the adsorbed particles more prone to agglomerate. However, since the same salt concentration is used within each category of experiments, the trend in dispersing performance of the lignosulfonates is likely to be less affected.

The degree of sulfonation per phenylpropane unit $(D)$ and the anionic charge of the lignosulfonates are given in Table 5. The degree of sulfonation is the ratio of the organic sulfur to the methoxyl content of the lignosulfonate [35], while the total anionic charge of the lignosulfonate was calculated using the formula:

$\rho_{L S}=\left(\frac{\mathrm{Org} \cdot S_{L S}}{M_{\text {Org. } S}}+\frac{\mathrm{COOH}_{L S}}{M_{\mathrm{COOH}}}+\frac{P h \cdot O H_{L S}}{M_{\text {ph.OH }}}\right)$

where $\rho$ refers to the total anionic charge and the subscript $L S$ to lignosulfonate; $\mathrm{Org} . S_{L S}, \mathrm{COOH}_{L S}$, and $\mathrm{Ph} . \mathrm{OH}_{L S}$ refer to the organic sulfur, carboxylic acid, and phenolic $\mathrm{OH}$ content of the lignosulfonate; $M_{\text {org.S }}, M_{\mathrm{COOH}}$, and $M_{p h . \mathrm{OH}}$ refer to the molecular weights of sulfur $(32.032 \mathrm{~g} / \mathrm{mol})$, carboxylic acid $(45.017 \mathrm{~g} / \mathrm{mol})$, and phenol $(94.11 \mathrm{~g} / \mathrm{mol})$, respectively. This is however a simplification since the total anionic charge is an average measured for the entire lignosulfonate sample, and within a lignosulfonate sample, there is a distribution of molecular weight as well as charge.

The criteria to evaluate lignosulfonate performance were based on combination of dispersant's ability to minimize aggregation/agglomeration of carbon black particles over time and its ability to reduce the viscosity of the carbon black dispersion. Particle size and rheology measurements (Figs. 6 and 10) indicate that DP-3537 is the most efficient lignosulfonate to disperse carbon black, followed by DP-3383. These two dispersants represent the lignosulfonates with a low degree of sulfonation ( $D=0.14$ for DP-3537 and $D=0.50$ for DP-3383). They however differ significantly in their molecular weights. DP-3537 has low molecular weight $\left(M_{w}=6000\right.$ $\mathrm{g} / \mathrm{mol})$, while DP-3383 has a high molecular weight $\left(M_{w}=\right.$ $77000 \mathrm{~g} / \mathrm{mol})$. Similarly, DP-3383 performs better than DP$3384\left(M_{w}=43000 \mathrm{~g} / \mathrm{mol}\right)$ and DP-3385 $\left(M_{w}=22000 \mathrm{~g} / \mathrm{mol}\right)$ despite having a higher molecular weight, thereby indicating that the degree of sulfonation of the dispersant plays a larger role in determining its effectiveness to disperse carbon black than molecular weight.

Since carbon black is a hydrophobic substrate, a more hydrophobic lignosulfonate is expected to perform as a better dispersant. The hydrophobicity of lignosulfonate depends on both the content of charged functional groups and molecular weight. A direct correlation between hydrophobicity and content of sulfonic acid and phenolic hydroxyl group has been reported [36]. As seen in Table 2, the variation in phenolic hydroxyl content between the lignosulfonate samples is less compared to variation in the sulfonyl group content. Thus, a lignosulfonate with low degree of sulfonation and high molecular weight is more hydrophobic [37]. The very low degree of sulfonation content in DP-3537 indicates that it is highly hydrophobic and therefore performs well as dispersant for carbon black. Similarly, the low degree of sulfonation and
Table 5 Degree of sulfonation and anionic charge of lignosulfonates

\begin{tabular}{llllll}
\hline \multirow{2}{*}{ Lignosulfonate } & \multirow{2}{*}{ Degree of sulfonation } & \multicolumn{2}{l}{ Anionic charge $(\mathrm{mmol} / \mathrm{g})$} \\
\cline { 3 - 6 } & & Sulfonyl & Carboxylate & Ph.OH & Total \\
\hline DP-3383 & 0.50 & 1.68 & 1.91 & 0.21 & 3.81 \\
DP-3384 & 0.65 & 1.78 & 2.22 & 0.17 & 4.17 \\
DP-3385 & 1.29 & 2.93 & 1.84 & 0.14 & 4.91 \\
DP-3537 & 0.14 & 0.65 & 3.31 & 0.20 & 4.17 \\
DP-3635 & 1.09 & 1.50 & 2.38 & 0.16 & 4.03 \\
DP-3760 & 0.68 & 1.62 & 2.27 & 0.18 & 4.07 \\
\hline
\end{tabular}

Ph.OH refers to phenolic hydroxyl 
high molecular weight makes DP-3383 hydrophobic. The lignosulfonates DP-3760 and DP-3384 have similar degree of sulfonation ( $D=0.65-0.68)$, but DP-3760 has a significantly higher molecular $\left(M_{w}=87000 \mathrm{~g} / \mathrm{mol}\right)$ weight than DP-3384 $\left(M_{w}=43000 \mathrm{~g} / \mathrm{mol}\right)$, thereby making it more hydrophobic than DP-3384. The remaining lignosulfonates, DP-3385 and DP-3635, have degree of sulfonation greater than 1 . However, a combination of high degree of sulfonation and low molecular weight makes DP-3385 hydrophilic, while a very high molecular weight makes DP-3635 hydrophobic. The observation that DP-3760 performs poorly despite being more hydrophobic than DP-3384 and DP-3385 indicates that a lignosulfonate with medium degree of sulfonation and high molecular weight performs poorly as a dispersant for carbon black. The rheology results corroborate the observation in particle size measurement.

Except for low molecular DP-3537, the viscosity of concentrated solutions of lignosulfonates in Fig. 12 increases with molecular weight. The viscosity of DP-3383 is higher than that of DP-3760 despite having a lower $M_{w}$. However, this could be due to a higher $M_{n}$ value for DP-3383 ( $M_{n}=3200$ $\mathrm{g} / \mathrm{mol})$ thereby indicating that on an average DP-3383 has molecules of higher molecular weight than DP-3760 $\left(M_{n}=\right.$ $2800 \mathrm{~g} / \mathrm{mol})$. In the case of low molecular DP-3537, intermolecular association via hydrogen bonding, Van der Waals forces, or hydrophobic interactions could be a reason for observation of high viscosity.

The adsorption isotherm of lignosulfonates on carbon black was inconclusive in predicting its dispersion efficiency. The adsorbed amount of lignosulfonate on carbon black did not show a correlation with molecular weight. Lignosulfonates have been reported to lie flat on the surface of carbon black, and the thickness of adsorbed layer is around $2 \mathrm{~nm}$, independent of their molecular weight [19]. Most likely, there is a difference in the way DP3635 adsorbs on the surface of carbon black compared to other lignosulfonates. High molecular weight lignosulfonates also have a tendency to exhibit flocculating properties $[38,39]$. It is possible that the very high molecular weight of DP-3635 has resulted in it simultaneously adsorbing on adjacent carbon black particles, which can be more pronounced in dispersion with high carbon black loading. In addition, the high polydispersity of the lignosulfonates $\left(M_{w} / M_{n}=3-83\right)$ used in this study makes the determination of area occupied by an adsorbed lignosulfonate molecule less reliable.

The zeta potential measurements indicated that the lignosulfonate does have the ability to enhance the stability of carbon black dispersion by electrostatic repulsion. Table 5 indicates that except for DP-3385, the total anionic charge of lignosulfonates is similar. Optical images of dilute carbon black dispersions indicate that dispersions with DP-3635 and DP-3760 show less stability despite having an absolute value of zeta potential greater than $30 \mathrm{~V}$ and being in similar range to zeta potential of carbon black with other adsorbed lignosulfonates. Thus, the most likely stabilization process is a combination of electrostatic stabilization and steric repulsion.

\section{Conclusion}

The influence of molecular weight and the degree of sulfonation of sodium lignosulfonates on its ability to disperse carbon black was investigated using particle size, adsorption isotherm, rheology, and zeta potential measurements. The results indicate that the degree of sulfonation plays a greater role in determining the efficiency of lignosulfonate to disperse carbon black than the molecular weight and hydrophobicity. A lignosulfonate with low degree of sulfonation is preferred to disperse carbon black. The most likely stabilization mechanism is a combination of electrostatic stabilization and steric repulsion.

Acknowledgements The authors are grateful for the financial support from Borregaard AS and Research Council of Norway (NFR grant no. 269570) and the technical support from Ross Ellis, Guro Fredheim, and Martin Andresen (Borregaard AS).

Funding Open access funding provided by NTNU Norwegian University of Science and Technology (incl St. Olavs Hospital Trondheim University Hospital).

\section{Declarations}

Disclosure The authors declare no competing interests.

Open Access This article is licensed under a Creative Commons Attribution 4.0 International License, which permits use, sharing, adaptation, distribution and reproduction in any medium or format, as long as you give appropriate credit to the original author(s) and the source, provide a link to the Creative Commons licence, and indicate if changes were made. The images or other third party material in this article are included in the article's Creative Commons licence, unless indicated otherwise in a credit line to the material. If material is not included in the article's Creative Commons licence and your intended use is not permitted by statutory regulation or exceeds the permitted use, you will need to obtain permission directly from the copyright holder. To view a copy of this licence, visit http://creativecommons.org/licenses/by/4.0/.

\section{References}

1. Kühner G, Voll M (1993) Manufacture of carbon black. In: Donnet J-B, Bansal RC, Wang M-J (eds) Carbon black science and technology. Marcel Dekker Inc, New York

2. Carbon Black User's Guide (2016) International Carbon Black Association - Safety. Health Environ Inf 36

3. Karl A et al (2002) US 6,451,100 B1 - Aqueous carbon black dispersions, U.S.P. Office, Editor. Degussa-Huls AG, United States 
4. Forrester RA, Ells PP (1964) US 3,118,844A - Preparation of carbon black dispersions, U.S.P. Office, Editor. Ashland Inc, United States

5. Ridaoui H, Jada A, Vidal L, Donnet JB (2006) Effect of cationic surfactant and block copolymer on carbon black particle surface charge and size. Colloids and Surfaces A: Physicochemical and Engineering Aspects 278(1-3):149-159

6. Medalia A, Hagopian E (1964) Dispersant-free aqueous slurries of carbon black. Viscosity, Techniques of Handling, and Use in Latex Masterbatching. Industrial \& Engineering Chemistry Product Research and Development 3(2):120-125

7. Medalia AI, Erivan H (1966) US 3,294,733A - Process of producing dispersant free carbon black slurries and rubber masterbatches containing same, U.S.P. Office, Editor. Cabot Corp

8. Eisermann C, Damm C, Winzer B, Peukert W (2014) Stabilization of carbon black particles with Cetyltrimethylammoniumbromide in aqueous media. Powder technology 253:338-346

9. Gupta SD, Bhagwat SS (2005) Adsorption of surfactants on carbon black-water interface. Journal of dispersion science and technology 26(1):111-120

10. Bystrzejewski M, Huczko A, Lange H, Gemming T, Büchner B, Rümmeli MH (2010) Dispersion and diameter separation of multiwall carbon nanotubes in aqueous solutions. Journal of Colloid and Interface Science 345(2):138-142

11. Zhao Y, Lu P, Li C, Fan X, Wen Q, Zhan Q, Shu X, Xu T, Zeng G (2013) Adsorption mechanism of sodium dodecyl benzene sulfonate on carbon blacks by adsorption isotherm and zeta potential determinations. Environmental technology 34(2):201-207

12. St A, Kleinhenz H, Karl A (2001) US 6,171,382 B1 - Aqueous carbon black dispersions, U.S.P. Office, Editor. Degussa-Huls AG

13. Sis H, Birinci M (2009) Effect of nonionic and ionic surfactants on zeta potential and dispersion properties of carbon black powders. Colloids and Surfaces A: Physicochemical and Engineering Aspects 341(1-3):60-67

14. Miano F, Bailey A, Luckham PF, Tadros TF (1992) Adsorption of nonyl phenol propylene oxide - ethylene oxide surfactants on carbon black and the rheology of the resulting dispersions. Colloids and surfaces 62(1-2):111-118

15. Thorn CE, Polakovic F, Mosolf CA (1995) US 5,476,580 A Processes for preparing a non-conductive substrate for electroplating, U.S.P. Office, Editor. OMG electronic Chemicals LLC

16. Fredheim GE, Christensen BE (2003) Polyelectrolyte complexes: interactions between lignosulfonate and chitosan. Biomacromolecules 4(2):232-239

17. Yan M, Yang D, Deng Y, Chen P, Zhou H, Qiu X (2010) Influence of $\mathrm{pH}$ on the behavior of lignosulfonate macromolecules in aqueous solution. Colloids and Surfaces A: Physicochemical and Engineering Aspects 371(1):50-58

18. Goring D (1962) The physical chemistry of lignin. Pure and applied chemistry 5(1-2):233-310

19. Goring DAI, Vuong R, Gancet C, Chanzy H (1979) The flatness of lignosulfonate macromolecules as demonstrated by electron microscopy. Journal of Applied Polymer Science 24(4):931-936

20. Myrvold BO (2008) A new model for the structure of lignosulphonates: Part 1. Behaviour in dilute solutions. Industrial Crops and Products 27(2):214-219

21. Vainio U, Lauten RA, Serimaa R (2008) Small-angle X-ray scattering and rheological characterization of aqueous lignosulfonate solutions. Langmuir 24(15):7735-7743
22. Qian $Y$ et al (2015) Light scattering characterization of lignosulfonate structure in saline solutions. Holzforschung, p 377

23. Chen J, Eraghi Kazzaz A, AlipoorMazandarani N, Hosseinpour Feizi Z, Fatehi P (2018) Production of flocculants, adsorbents, and dispersants from lignin. Molecules 23(4):868

24. Qin Y, Yang D, Gu F, Li X, Xiong W, Zhu JY (2016) Biorefinery lignosulfonates as a dispersant for coal water slurry. Sustainable Chemical Processes 4(1):5

25. Zhou M, Qiu X, Yang D, Lou H (2006) Properties of different molecular weight sodium lignosulfonate fractions as dispersant of coal-water slurry. Journal of dispersion science and technology 27(6):851-856

26. Li S, Liu S, Fu Z, Li Q, Wu C, Guo W (2017) Surface modification and characterization of carbon black by sodium lignosulphonate. Surface and Interface Analysis 49(3):197-204

27. Balasooriya $\mathrm{W}$ et al (2019) The effect of the surface area of carbon black grades on HNBR in harsh environments. Polymers 11(1)

28. Cabot (2016) Product Specifications: Black Pearls 430 Speciality Carbon Black

29. Myrvold Bernt O (2013) Salting-out and salting-in experiments with lignosulfonates (LSs). Holzforschung, p 549

30. Brunauer S, Emmett PH, Teller E (1938) Adsorption of gases in multimolecular layers. Journal of the American Chemical Society 60(2):309-319

31. Adler E (1977) Lignin chemistry — past, present and future. Wood Science and Technology 11(3):169-218

32. Fonte P et al (2012) Chapter fifteen - Chitosan-coated solid lipid nanoparticles for insulin delivery. In: Düzgüneș N (ed) methods in enzymology. Academic Press, pp 295-314

33. Ragnar M, Lindgren CT, Nilvebrant N-O (2000) pKa-values of guaiacyl and syringyl phenols related to lignin. Journal of Wood Chemistry and Technology 20(3):277-305

34. Andreasson B, Wågberg L (2009) On the mechanism behind the action of wet strength and wet stregth agents. In: Ek M, Gellerstedt G, Henriksson G (eds) Paper products physics and technology. Walter de Gruyter GmbH \& Co. KG, Berlin

35. Fredheim GE, Christensen BE, Braaten SM (2003) Comparison of molecular weight and molecular weight distributions of softwood and hardwood lignosulfonates. Journal of Wood Chemistry and Technology 23(2):197-215

36. Pang Y et al (2016) Relationship between the hydrophilicity of lignin dispersants and their performance towards pesticide particles. Holzforschung, p 653

37. Winowiski T et al (2005) Characterization of sulfonated lignin dispersants by hydrophobic interactive chromatography. Journal of ASTM international 2(9):1-6

38. Le Bell JC (1984) The relation between the structure of lignosulphonates and their effect as stabilizers for latex particulate dispersions. Colloids and Surfaces 9(3):237-251

39. Gundersen SA, Sjöblom J (2001) Lignosulfonates and Kraft lignins as $\mathrm{O} / \mathrm{W}$ emulsion stabilizers studied by means of electrical conductivity. In: Sjöblom J (ed) Encyclopedic Handbook of Emulsion Technology. Marcel Dekker, Inc., New York, pp 361-375

Publisher's note Springer Nature remains neutral with regard to jurisdictional claims in published maps and institutional affiliations. 